\title{
Input versus output controls as instruments for fisheries management with a focus on Mediterranean fisheries.
}

Running title: Input vs output technical measures.

Jose M. Bellido ${ }^{1,2, *}$, U. Rashid Sumaila ${ }^{2}$, Jose Luis Sánchez-Lizaso ${ }^{3}$, Maria Lourdes Palomares $^{2}$ and Daniel Pauly ${ }^{2}$

${ }^{1}$ Instituto Español de Oceanografía, Centro Oceanográfico de Murcia. C/Varadero 1, 30740 San Pedro del Pinatar, Murcia, Spain.

${ }^{2}$ Institute for the Oceans and Fisheries, University of British Columbia, Vancouver, BC, Canada

${ }^{3}$ Departamento de Ciencias del Mar y Biología Aplicada, Universidad de Alicante, POB 99, 03080 Alicante, Spain

*Correspondence

Dr. Jose M. Bellido (josem.bellido@ieo.es)

\begin{abstract}
Article 4 of EU Regulation 1380/2013 on the Common Fisheries Policy (CFP) define 'technical measure' as "a measure that regulates the composition of catches by species and size and the impacts on components of the ecosystems resulting from fishing activities by establishing conditions for the use and structure of fishing gear and restrictions on access to fishing areas." Thus, these are a set of rules that govern where, when and how fishing can take place. Most of the fisheries management systems in place worldwide employ technical measures based on control of inputs and outputs. For Europe, the European Commission is reforming the CFP legislative framework and has updated and amended the rules for technical measures (EU Regulation 2019/1241). This is particularly important for management systems in the European parts of the Mediterranean, where input measures play a major role, in contrast to management systems in the North East Atlantic, which uses mainly output measures (catch quota).
\end{abstract}

We discuss here the main advantages and disadvantages of these instruments with a particular focus on the European part of the Mediterranean Sea, our main aim being to foster a debate on the best measures for fisheries management.

Keywords: fishing effort, quota, technical measures, fishery policy, enforcement.

\section{What are technical measures?}

Technical measures are restrictive by nature. They establish a standardization in fishing practices with the goal of ensuring sustainability and usually adding extra costs to fishing operations (Suuronen and Sarda, 2007). Thus, fishers' economic gains are not ensured in all cases. However, technical measures, which may generate losses in the short and medium term, tend to generate gains in the long term (Sumaila 2004; Sumaila 
Bellido JM, Sumaila UR, Sanchez-Lizaso JL, Palomares ML, Pauly D (2020). Input versus output controls as instruments for fisheries management with a focus on Mediterranean fisheries. Marine Policy, https://doi.org/10.1016/j.marpol.2019.103786

et al., 2012). Implementing technical measures becomes very complicated when fish stocks are overexploited, particularly where fisheries are heavily subsidized (Milazzo, 1998; Sumaila et al., 2016, 2019; Sala et al., 2018). In this case, managers must choose what to protect: fish or fishers? In the short term, what is good for fishers is bad for fish populations. This, however, if continued over the long-term, will end up being bad for fishers as well. This implies that the usually expressed choice between fish and fishers is misleading, except in the short term - for fishers to thrive over time, the sustainability of fish stocks is crucial, i.e., no fish $=$ no fishers!

The use of technical measures is not always successful. Every new technical measure (particularly those not readily accepted by fishers) prompts a reaction to circumvent the rule, or at least to limit its effect. Technical measures are supposed to be efficient and dynamic, such as to be able to regulate a continually evolving sector. However, they can become obsolete when new technical development occurs.

Technical measures can help mitigate the ecosystem impact of fisheries, which are often associated with fishing efficiency, i.e., technology creep and fishing gear improvements (Palomares and Pauly, 2019) or limit the access of given areas to fisheries (i.e., marine fisheries and fishing agreements). Bellido et al., (2015) suggests a classification which should reasonably account for both the required clarity in terminology and the underlying high complexity (see Bellido et al., 2015 for a detailed explanation on each group of technical measures):

- Regulations of fleet characteristics and technical characteristics of the gears. These technical measures are instruments of input control addressing the question "How to catch the fish?" These measures can be split into two groups based on:

- Technical characteristics, length and engine power of fishing vessels;

- Technical and operational characteristics of fishing gears.

- Regulations of fleet access to fishing grounds. These technical measures are instruments of input control addressing the question "When and where to catch the fish?" They can be split into two groups:

- Control of fishing time by day and by week among others;

- Spatial and/or seasonal restrictions to fishing in specific areas or seasons of the year.

- Regulations of what can be caught and what can be retained onboard. These technical measures are instruments of output control addressing the question "What and how much to catch?" They can be split into the following three groups:

- Catch composition: allowed, vulnerable and prohibited species;

- Commercial minimum sizes (Minimum Landing Size, MLS; renamed as Minimum Conservation Reference Size, MCRS);

- Quotas and catch limits.

\section{Input versus Output control}

Technical measures are often referred to as instruments of input and/or output controls. Input controls are the mechanisms that regulate the fishing effort going into the fishery, 
Bellido JM, Sumaila UR, Sanchez-Lizaso JL, Palomares ML, Pauly D (2020). Input versus output controls as instruments for fisheries management with a focus on Mediterranean fisheries. Marine Policy, https://doi.org/10.1016/j.marpol.2019.103786

i.e., capacity, areas, seasons and time of fishing. Output controls govern the outcomes of the fishery, i.e., catch that results from fishing effort, among them catch composition, allowed sizes and species and quotas or catch limits.

Input controls are key measures for fishing management. They are easy to measure as they are quantifiable (fishing capacity, dimension of gears, mesh, hooks, fishing times, access to fishing grounds, etc.). Another advantage of input controls is that they occur prior to a fishing activity, so both fishers and managers can plan their respective activities according to known rules. As a disadvantage, input controls have to be clearly defined for all fishing processes and enforcement rules should be well-known and fulfilled (Johnsen and Eliasen, 2011). Input controls need clear definitions and determinations on fishing capacity and effort applied to every fishing ground and their changes with time. Fishing is a very dynamic activity which evolves continuously, searching for maximum efficiency. This includes improvements in the detection of fish, engines, accessing previously inaccessible areas, better selectivity of fishing gear, new materials, new electronics, etc. As a result, technical measures must be linked to the reality of fishing operations, and thus, they incur the risk of rapid obsolescence, becoming useless in some cases or even harmful in the worst cases. Innovation and technology is pervasive in our lives and progress is also present in fishing technology. To compensate for unavoidable catchability increases with time (Palomares and Pauly, 2019), input controls must be periodically revised. This may be done by the introduction of the concept of yearly Total Allowable Effort (TAE) on the basis of scientific advice that has been recently established for the Mediterranean demersal fisheries (EU, 2019b) and it will be enforced on January $1^{\text {st }} 2020$.

Output controls are also useful technical measures for fisheries management. They establish a clear framework for fishing, creating production limits for fish exploitation. These may also provide incentives to the fishing industry to develop technology to achieve agreed aims (STECF, 2013). However, by their nature, they occur after fishing has taken place. Fishers must comply with output measures (allowed size, allowed catch, etc.), otherwise they will be fined. If fishers' compliance is not ensured, output controls do not work, and the fishery becomes difficult to control, monitor and assess. This applies especially in cases of Illegal, Unreported and Unregulated (IUU) fishing, when black markets or species substitution occur and juveniles are caught illegally (Bellido et al, 2017; Jacquet and Pauly, 2008). In multispecies fisheries, output controls may choke the multispecies TAC fishery once a TAC of one of the target species is achieved, favouring discards of target species or even prompting the closure of that multispecies fishery (Hatcher, 2014).

Traditional fisheries management focuses on individual fish stocks with the main objective of ensuring the sustainable exploitation of that stock. Thus, it is important to ensure that the catch is limited in some way so that sufficient fish biomass is left to allow the stock to grow and reproduce. In principle, this can be achieved directly by either specifying a limit on the total amount of fish that can be caught or by limiting the number of boats and/or the amount of time spent fishing.

However, those sustainable levels should be scientifically set. Reference points, such as minimum biomass levels and target fishing mortality, are important indicators to achieve Maximum Sustainable Yield (MSY) by proper harvest strategies (EU, 2013; 
Bellido JM, Sumaila UR, Sanchez-Lizaso JL, Palomares ML, Pauly D (2020). Input versus output controls as instruments for fisheries management with a focus on Mediterranean fisheries. Marine Policy, https://doi.org/10.1016/j.marpol.2019.103786

EU, 2019a; EU, 2019b). This is a major topic in EU CFP objectives as "the current policy stipulates that between 2015 and 2020 catch limits should be set that are sustainable and maintain fish stocks in the long term" (EU, 2013). However it remains still unclear if this objective can be fulfilled, particularly within that time framework.

Additionally, current management is not aimed only at sustainable catches. Rather, the Ecosystem Approach to Fisheries Management (EAFM) is gaining more importance; it is currently implied in European fisheries management regulations. There is an increasing commitment to environmental concerns, such as protection of marine habitats and ecosystems and vulnerable species. Some examples include the implementation of the EU Marine Strategy Directive and other international commitments (Bonn Convention on Biological Diversity, CBD) or 'soft law', such as, the FAO International Plan of Action for Reducing Incidental Catch of Seabirds in Longline Fisheries (IPOA-Seabirds). It is in this context that technical measures have a greater role to play.

\section{A compromise of a common framework with geographical peculiarities.}

Regionalisation should be a major concern on any fishery policy regulation that takes into account each region's characteristics and peculiarities (Uhlmann et al., 2013). European waters and the EU Common Fishery Policy is a good example. The vast extension of European fisheries produces different management systems which indeed are needed for a strong regional cooperation to succeed. This requirement is now included in the EU regulation, encouraging Member States (MS) to submit joint recommendations when they have a direct management interest (EU, 2019b). Many of these MS joint recommendations become formal law via EU Delegated Acts.

Thus, a balance between regionalisation and integrative European management should be found. In some cases, solutions that are useful and effective in the Atlantic, or Baltic or Mediterranean may not fit other fisheries in the European Union. However, it will be worth taking into account experience from the different maritime regions and then tuning the management systems according to the needs of each fishing area (Johnsen and Eliasen, 2011).

The EU has a great diversity among its different regional seas, which range from polar to subtropical waters, notably of fish species, which increases from cold to warmer waters. European ecosystem diversity is also apparent in European fisheries and is best exemplified by comparing the Baltic with the Mediterranean.

The structure of the fisheries in the Baltic is relatively simple, with three main species (herring, sprat and cod) accounting for 95\% of the catch (ICES, 2017). Minimum sizes (MCRS) are established for only 8 species and the Multi Annual Plan (MAP) for the stocks of cod, herring and sprat in the Baltic Sea applies to seven species, comprising both target and by-catch species in the whole basin (EU, 2016). The fleet is relatively small, with approximately 4900 active fishing boats in the nine EU countries in the Baltic Sea (ICES 2018, EUROSTAT European Statistics https://ec.europa.eu/eurostat). The fleet also uses similar gears throughout the basin (Stepputtis et al., 2015). These characteristics make the Baltic Sea ideal for output control management approaches, where quotas can be reasonably enforced. 
Bellido JM, Sumaila UR, Sanchez-Lizaso JL, Palomares ML, Pauly D (2020). Input versus output controls as instruments for fisheries management with a focus on Mediterranean fisheries. Marine Policy, https://doi.org/10.1016/i.marpol.2019.103786

In contrast, the Mediterranean shows a high diversity both in species and fishing patterns, with a vast geographical dispersion of landing sites and islands, many of which have small-scale fleets. In contrast to the Baltic MAP, the Mediterranean demersal MAP applies to 6 major target species and by-catch of up to 120 species (EU, 2019b; Bellido et al., 2014). MCRS are setup for 27 species and the fleet is comprised of over 38000 active fishing boats, accounting for $46 \%$ of total EU fishing vessels (Bellido et al., 2014; Eurostat, 2019). Additionally, Mediterranean weather conditions allow more effective fishing days along the year, in contrast to the Baltic Sea where weather is more unstable and with ice covering a large part of the northern areas in winter. Therefore, considering all these peculiarities, a management system more focussed on input control is likely to be more implementable and enforceable in the Mediterranean (Pauly, 1996). However, scarcity of available infrastructure for control and surveillance are likely to influence the level of compliance of regulations, both for input and output controls. In many cases, inspectors are few and lack the support needed to cover and control the vast areas in their purview, e.g., in the Aegean Sea with hundreds of islands and landing sites. Remote sensing monitoring, real time control, camera devices, vessel control navigation and positioning systems should be explored with regard to their potential for ensuring adequate compliance of technical measures and fishing operations.

Stock abundance levels change with time and fishing possibilities have to adapt to these changes. Since not all the technical measures have the same flexibility, it is often necessary to combine longer-term measures (i.e., closed areas to protect sensitive ecosystems, gear selectivity regulation, fishing power control) with others that may change according to stock condition (i.e., TAC, fishing time). This is of particular concern for the Mediterranean, notably because the last report on Mediterranean stocks status of the Scientific, Technical and Economic Committee for Fisheries (STECF) report that only 6 of 47 stocks are healthy, while the majority are overfished (STECF, 2018).

Transferability of fishing rights could be also an intelligent instrument to manage fishing effort within sustainable limits. The number of fishing boats is continuously decreasing in the Mediterranean in the last decades (Eurostat, 2019) and it is quite evident that neither the ecosystem nor the production system can afford more active operators. Additionally as aforementioned, a maximum fishing effort system is to be set as of January 2020, mainly based on number of boats and fishing days allowed. However, the issuing of new fishing licences is a national administration prerogative and can produce distortions in the total management effort system, particularly since January 2020 when the yearly maximum TAE will be applied. On the other hand, fishing rights transferability may also produce other adverse effects; probably the most perverse is the concentration of fishing rights in the hands of a few powerful and bigger and bigger ship-owners.

Hence, Mediterranean fisheries face a crucial challenge: where accurate fishing management is essential to reverse their currently dismal situation. In our opinion, a more adaptive and regionalized fisheries management could lead to a significant reduction in the need for technical measures (Stepputtis et al., 2015). We believe that it is better to rely on a reduced number of realistic and pragmatic regulations with a good degree of compliance than to develop an extensive framework that will lead to a high 
Bellido JM, Sumaila UR, Sanchez-Lizaso JL, Palomares ML, Pauly D (2020). Input versus output controls as instruments for fisheries management with a focus on Mediterranean fisheries. Marine Policy,

https://doi.org/10.1016/j.marpol.2019.103786

level of non-compliance. Bellido et al (2015) detailed specific recommendations for technical measures in the Mediterranean, we summarize some of them here:

- Strengthen control on vessels' capacity and power, e.g., when vessels power (HPs) are over dimensioned.

- Technology is needed in all agents, from fishers to inspectors for a sustainable fishing. Increasing effort due to technology creep is an important risk. Some gear modifications and devices for discard mitigation should be applied, such as separator panels or sorting grids.

- Regulation of fishing time is one of the most important technical measure, although sometimes producing conflicts. Some studies estimated that a reduction of 1 day per week is more positive, and also easier to enforce, than a reduction of daily fishing hours (Samy-Kamal et al, 2015; Sanchez Lizaso et al., 2018).

- Spawners should be protected with good planning of temporal (seasonal) closures. These temporal closures should be for all fisheries at the same time. More marine reserves are needed in the Mediterranean, particularly in offshore waters where additional knowledge of deep marine habitats is needed.

- Protection of waters shallower than $50 \mathrm{~m}$ and deeper than $1000 \mathrm{~m}$ is essential and should be guaranteed. Depth is the most important factor for fisheries spatial planning (Bellido et al, 2019).

- Better spatial marine planning is needed. Fishery management has to be also mobile and dynamic in some extend. Of course, this new framework should ensure that the principles of conservation and sustainability are met.

\section{Acknowledgements}

All authors contributed to the paper. JMB wrote the first draft of text and RS, JLS, MLP and DP contributed to the text. The manuscript also benefited from valuable comments of two anonymous reviewers. JMB wrote this article during a sabbatical at UBC, funded by the Spanish Ministry of Education (Convocatoria MECD Salvador de Madariaga, 2017, Ref. PRX17/00355). This article is mainly based on the analysis in "Fishing management based on technical measures - the need of a new framework for the Mediterranean Sea", which was requested by the European Parliament's Committee on Fisheries and presented at the "Workshop on a new technical measures framework for the new Common Fishery Policy" at the European Parliament in Brussels on 13th October 2015. We acknowledge the financial support provided by the European Parliament for carrying out this work. MLP and DP are supported by the Sea Around Us, a research initiative funded by several philanthropic foundations, notably the Oak Foundation, David and Lucille Packard Foundation, Bloomberg Foundation via Rare, Oceana, Marisla Foundation, Paul M. Angell Family Foundation, and MAVA Foundation. RS is supported by SSHRC, MEOPAR and Genome Canada and BC.

\section{References}

$\checkmark$ Bellido JM, A. Carbonell, M. Garcia, T. Garcia and M. González, 2014. The obligation to land all catches - consequences for the Mediterranean. In-depth analysis. European Parliament, Policy Department B: Structural and Cohesion Policies, Brussels 52 pp, Publication year: 2014 http://bookshop.europa.eu/en/the-obligation-to-land-all-catches-consequences-for-themediterranean-pbQA0114340/, ISBN: 978-92-823-5604-3, DOI: 10.2861/59268 
Bellido JM, Sumaila UR, Sanchez-Lizaso JL, Palomares ML, Pauly D (2020). Input versus output controls as instruments for fisheries management with a focus on Mediterranean fisheries. Marine Policy,

https://doi.org/10.1016/i.marpol.2019.103786

$\checkmark \quad$ Bellido, JM., JL. Sanchez, A. Carbonell, T. Garcia, J. Baro and J. Valeiras, 2015. Fishing management based on technical measures - the need of a new framework for the Mediterranean Sea. 131-170p. In "Workshop on a new technical measures framework for the new Commom Fishery Policy." Study for the European Parliament, Committee on fisheries, Brussels, October 2015, 172pp. ISBN 978-92-823-8100-7 (pdf); doi 10.2861/650920 (pdf). Available at http://www.europarl.europa.eu/supporting-analyses

$\checkmark$ Bellido JM, M. García-Rodriguez, T. García-Jiménez, M. González-Aguilar, A. CarbonellQuetglas, 2017. Could the obligation to land undersized individuals increase the black market for juveniles: evidence from the Mediterranean?. Fish and Fisheries, 18(1): 185-194 p, DOI: http://dx.doi.org/10.1111/faf.12166.

$\checkmark$ Bellido JM, I Paradinas, R Vilela, G Bas, MG Pennino, 2019. A marine spatial planning approach to minimize discards: Challenges and opportunities of the Landing Obligation in European waters, 239-256 p. In S.S. Uhlmann, C. Ulrich, S.J. Kennelly (Eds.), The European Landing Obligation - Reducing discards in complex, multi-species and multi-jurisdictional fisheries. Cham: Springer, 438 pp. https://doi.org/10.1007/978-3-030-03308-8_12

$\checkmark$ Colloca, F, Cardinale, M, Maynou, F, Giannoulaki, M, Scarcella, G, Jenko, K, Bellido, JM \& Fiorentino, F, 2011. Rebuilding Mediterranean fisheries: a new paradigm for ecological sustainability. Fish and Fisheries, DOI: 10.1111/j.1467-2979.2011.00453.

$\checkmark$ EU, 2013. Regulation (EU) No 1380/2013 of the European Parliament and of the Council of 11 December 2013 on the Common Fisheries Policy

$\checkmark$ EU, 2016. Regulation (EU) 2016/1139 of the European Parliament and of the Council of 6 July 2016 establishing a multiannual plan for the stocks of cod, herring and sprat in the Baltic Sea and the fisheries exploiting those stocks.

$\checkmark$ EU, 2019a. Regulation (EU) 2019/1241 of the European Parliament and of the Council of 20 June 2019 on the conservation of fisheries resources and the protection of marine ecosystems through technical measures.

$\checkmark$ EU, 2019b. Regulation (EU) 2019/1022 of the European Parliament and of the ouncil of 20 June 2019 establishing a multiannual plan for the fisheries exploiting demersal stocks in the western Mediterranean Sea.

$\checkmark$ Eurostat, 2019. European Statistics website. https://ec.europa.eu/eurostat . Last accessed, October $21^{\text {st }} 2019$.

$\checkmark$ Hatcher, A., 2014. Implications of a Discard Ban in Multispecies Quota Fisheries. Environmental and Resource Economics, https://doi.org/10.1007/s10640-013-9716-1

$\checkmark \quad$ ICES, 2017. ICES Fisheries Overviews, Baltic Sea Ecoregion. Published 20 December 2017. DOI: $10.17895 /$ ices.pub.3053

$\checkmark \quad$ ICES, 2018. ICES Fisheries Overviews, Baltic Sea Ecoregion. Published 31 May 2018. https://doi.org/10.17895/ices.pub.4389

$\checkmark$ Jacquet, J. and D. Pauly. 2008. Trade secrets: renaming and mislabeling of seafood. Marine Policy 32: 309-318. doi 10.1016/j.marpol.2007.06.007.

$\checkmark$ Johnsen, J. P. and Eliasen, S. 2011. Solving complex fisheries management problems: what the EU can learn from the Nordic experiences of reduction of discards. Marine Policy, 35: 130-139.

$\checkmark$ Milazzo, M., 1998. Subsidies in world fisheries: a reexamination. The World Bank. ISBN: 9780-8213-4216-9. https://doi.org/10.1596/0-8213-4216-9

$\checkmark$ Palomares, M.L.D, D. Pauly. 2019. On the creeping increase of vessels' fishing power. Special issue on "Managing local and global fisheries in the Anthropocene". Ecology and Society 24 (3): 31; www.ecologyandsociety.org/vol24/iss3/art31/.

$\checkmark$ Pauly, D. 1996. ITQs: the assumptions behind the meme. Reviews in Fish Biology and Fisheries 6: 109-112

$\checkmark$ Sala, E., J. Mayorga, C. Costello, D. Kroodsma, M. L. D. Palomares, D. Pauly, U. Rashid Sumaila, D. Zeller, 2018. The economics of fishing the high seas. Sci. Adv. 4, eaat2504 (2018). DOI: $10.1126 /$ sciadv.aat2504

$\checkmark$ Samy-Kamal, M., A. Forcada, J.L. Sánchez Lizaso, 2015. Daily variation of fishing effort and ex-vessel prices in a western Mediterranean multi-species fishery: implications for sustainable management. Marine Policy. 61, pp. 187 - 195.

$\checkmark$ Sánchez Lizaso, J.L. I. Sola, E. Guijarro-García, F. González-Carrión, R. Franquesa J.M. Bellido, 2018, Research for PECH Committee Discard ban, Landing Obligation and MSY in the Western Mediterranean Sea - the Spanish Case, European Parliament, Policy Department for Structural and Cohesion Policies, Brussels ISBN 978-92-846-4118-5 doi:10.2861/20951 
Bellido JM, Sumaila UR, Sanchez-Lizaso JL, Palomares ML, Pauly D (2020). Input versus output controls as instruments for fisheries management with a focus on Mediterranean fisheries. Marine Policy,

https://doi.org/10.1016/j.marpol.2019.103786

$\checkmark$ STECF, 2013. Different Principles for defining selectivity under the future TM regulation (STECF-13-04). Publications Office of the European Union, Luxembourg, EUR 25973 EN, JRC 81584.

$\checkmark$ STECF, 2018. Monitoring the performance of the Common Fisheries Policy (STECF-Adhoc-1801). Publications Office of the European Union, Luxembourg, 2018, ISBN 978-92-79-85802-4, doi:10.2760/329345, JRC111761.

$\checkmark$ Stepputtis, D., C. Zimmermann, U. Krumme and C. von Dorrien, 2015. Technical measures in the baltic sea - An alternative to over-regulation and the brace-and-belt approach. 41-84p. In "Workshop on a new technical measures framework for the new Commom Fishery Policy." Study for the European Parliament, Committee on fisheries, Brussels, October 2015, 172pp. ISBN 978-92-823-8100-7 (pdf); doi 10.2861/650920 (pdf). Available at http://www.europarl.eruropa.eu/supporting-analyses

$\checkmark \quad$ Sumaila, U.R., 2004. Intergenerational cost benefit analysis and marine ecosystem restoration. Fish and Fisheries, 5, 329-343.

$\checkmark \quad$ Sumaila, U.R., Cheung, W.W.L., Dyck, A., Gueye, K., Huang, L., Lam, V.W.Y., Pauly, D., Srinivasan, T., Swartz, W., Pauly, D., and Zeller, D., 2012. Benefits of rebuilding global marine fisheries outweigh costs. PLoS ONE 7(7), e40542, DOI: 10.1371/journal.pone.0040542

$\checkmark \quad$ Sumaila, U. R., Lam, V., Le Manach, F., Swartz, W., and Pauly, D., 2016. Global fisheries subsidies: An updated estimate. Marine Policy, 69, 189-193.

$\checkmark$ Sumaila, U.R., Ebrahim, N, Schuhbauer, A., Skerritt, D., Li, Y., Kim, H.S., Mallory, T.G., Lam, V.W.L., Pauly, D., 2019. Updated estimates and analysis of global fisheries subsidies. Marine Policy, 109 (2019), p. 103695, 10.1016/j.marpol.2019.103695

$\checkmark$ Suuronen, P. and Sarda, F., 2007. The role of technical measures in European fisheries management and how to make them work better. ICES Journal of Marine Science, 64(4), 751756.

$\checkmark$ Uhlmann, S. S., van Helmond, A. T. M., Stefánsdóttir, E. K., Sigurðardóttir, S., Haralabous, J., Bellido, J.M, Carbonell, A., Catchpole, T., Damalas, D., Fauconnet, L., Feekings, J., Garcia, T., Madsen, N., Mallold, S., Margeirsson, S., Palialexis, A., Readdy, L., Valeiras, J., Vassilopoulou, V., and Rochet, M-J.. 2013. Discarded fish in European waters: general patterns and contrasts. ICES J. Mar. Sci. doi:10.1093/icesjms/fst030.

\section{Author contribution}

All authors contributed to the paper. JMB wrote the first draft of text and RS, JLS, MLP and DP contributed to the text.

\section{Author statement regarding data sharing}

No research data was used for the research described in the article. 